\title{
Social change design: Disrupting the benchmark template
}

\author{
Authors: \\ Dr Marie-Louise Fry - Griffith University, Australia \\ Dr Josephine Previte - The University of Queensland, Australia \\ Professor Linda Brennan - RMIT, Australia
}

\begin{abstract}
Purpose - This paper proposes a new ecologically systems-driven framework, underpinned by a relational marketplace lens, for social marketing practitioners to consider when planning and designing programs. We contend that behavioural change does not occur in a vacuum and, as such, point to an ecology where the individual is but one participant in a broader scope of social change activities.
\end{abstract}

Design/Methodology/approach - The paper is conceptual and presents the Indicators for Change Framework.

Findings - The Indicators for Social Change Framework puts forward a series of 'must have' indicators to consider when designing and planning social marketing programs. Across identified indicators the Framework delineates types of marketing actions to consider when planning for individual-oriented change and those required for wider systems-oriented change.

Originality/value - This paper contributes to the broadening and deepening of social marketing arguing that reliance on individual behaviour change perspectives is not sufficient to resolve complex social problems that are inherently influenced by wider social forces. In transforming social change design we transition towards a logic view of social marketing that encourages and supports social change planners to be inclusive of interactions, processes and outcomes of value creation across the wider social marketing system.

Key words: benchmark criteria, social change indicators, ecological systems, alcohol

Paper type: Conceptual

To cite this paper please use the following:

Fry, M.L., Previte, J. \& Brennan, L. (2017), 'Social change design: Disrupting the benchmark template', Journal of Social Marketing,7(2):214-218 http://dx.doi.org/10.1108/JSOCM-10$\underline{2016-0064}$ 


\section{Introduction}

Contemporary debate within social marketing argues for a transitioning beyond a micromanagerial perspective, focusing solely on influencing downstream individual behaviour towards more thoughtful consideration of relational interactions between individuals within complex market systems (Brennan et al., 2016; Domegan et al., 2016). This paper engages the current discussion about broadening 'what is social marketing' beyond the current 'benchmark’ codification of social marketing (Andreasen, 2002; French and Blair Stevens, 2005). The emergence of benchmarking criteria - as outlined by Andreasen (2002) and the National Social Marketing Centre (French and Blair-Stevens, 2005) - were pertinent at a time when definitional certainty was needed during the 'growth phase' of social marketing. Notably, the fact that we can now benchmark activities illustrates that social marketing, as a discipline, has reached a greater maturity. Yet, the application and utility of NSMC criteria in an era where social marketing has evolved significantly as a discipline in contributing to social, as opposed to individual, change is questioned (Dibb, 2014).

While Andreasen's and the NSMC's benchmark criteria have been well received and globally applied, they are largely interpreted from a down-stream micro-managerial individual behaviour change perspective. This is despite Kotler and Zaltman’s (1971) seminal article advocating for a wider application of marketing to address social change situations. An individual behaviour change objective may be a goal of a social marketing program, yet it represents just one approach to social marketing. When it comes to creating change within social markets (or an eco-system) there is more than one type of market to consider. For example, there are differences in the way actors and stakeholders participate in social change approaches to address problems in established consumption markets such as alcohol, food or tobacco. As such, a markets-based social change purview extends conceptualisation of social marketing as a set of value shaping activities requiring the intersection of multiple layers and 
actors in the eco-system all with (different) goals and objectives (Brennan et al., 2016; Domegan et al., 2016). In this way, the behaviour change lens transitions from creating individual behaviour change to a mindset that shapes social change.

Appreciative of the intent behind Kotler and Zaltman's call to address 'social change', in this paper our goal is to broaden the mindset of social marketing to account for system dynamics, because individual behaviour change is not sufficient to resolve system-wide concerns that occur in complex social marketing situations (Biroscak et al., 2014). We do not argue that individual behaviour change is redundant or no longer useful. Moreover, we contend that when it comes to shaping markets a one-size fits all benchmark criteria does not sufficiently address complex problems that social markets often face. Reliance on micro social marketing that influences individual behaviour and specification of benchmark criteria codifying 'what is' social marketing limits the potential and opportunities of social marketing as a 'social change' framework. Continuing the debate as to the nature and scope of the landscape that social marketing occupies has critical importance for the application, range and design of social change programs. In this regard, the paper contributes to the broadening and deepening of social marketing as a facilitator of marketplace social change (for example Gordon et al., 2016; Brennan et al., 2016; Domegan et al., 2016; Dibb, 2014; Fry, 2014; Lefebvre, 2012).

The paper is organised as follows: First, we briefly summarise the key purpose and limitations of the current social marketing benchmarks. Second, we illustrate, through a case study, the utilitarian reductionist nature of the benchmark criteria as a check list set of specific activities that fulfils the task of programs meeting, or not meeting, the social marketing label. Finally, in disrupting the benchmark template, we specifically argue for social change design and planning to better incorporate an ecological system wide lens to conceptualise social marketing's capacity to influence social change. In doing so, we put forward an 'Indicators 
for Social Change' Framework to guide program design and planning that addresses change at different levels within an ecosystem. Our aim in putting forward 'Indicators for Social Change' is to transition towards a logic of social marketing that encourages and supports social change planners to be inclusive of interactions, processes and outcomes of value creation across the wider social marketing system.

\section{Reflecting on the “current” social marketing benchmarks}

Articulation of the social marketing benchmark criteria played an important role in the early debate as to 'what is' and 'what is not' social marketing (Dibb, 2014). The criteria served an important function in legitimising social marketing’s authenticity as a credible entrant within the social change sphere. Attention was directed to social marketing's distinction as the application of marketing tools to foster social good and the knowledge on which it is based. In defining what he termed legitimate social marketing, Andreasen (2002) originally proposed six benchmarks - behaviour change, audience research, segmentation, exchange, marketing mix and competition - advocating behaviour change as 'at the core' of any social marketing initiatives. Andreasen's original criteria have been the foundation for subsequent efforts to categorise the scope and domain of social marketing.

The UK National Social Marketing Centre (NSMC) later refined the criteria by contributing two additional benchmarks (customer orientation and insight) to encourage and reassure UK government stakeholders of the legitimacy of using social marketing to address social change within a health policy domain (French and Blair-Stevens, 2005). In delineating the value of social marketing to health professionals, French and Blair-Stevens established a 'social marketing mind-set' and nomenclature around social change activities that has been adopted widely throughout social marketing research and practice. While the NSMC template has been used to design social change programs (Rundle-Thiele et al., 2013; Llaurado et al., 
2015) the criteria are principally utilised as a checklist tool to determine if a program is legitimately social marketing (Dooley et al., 2006; Merritt et al., 2009) or to determine the extent to which social marketing programs are effective in comparison to other approaches (Gracia-Marco et al., 2011). It is not surprising given the premise on which social marketing benchmark criteria were developed that they have been co-opted as a tool that either confirms, or not, the extent to which an intervention aligns with a 'one size fits all' perspective of 'what is’ social marketing.

More recently the benchmark criteria have been criticised for: 1) including disparate criteria of higher-order principles that underpin marketing such as customer orientation and exchange - interspersed with discrete marketing activities such as audience research, marketing mix, segmentation), 2) not differentiating the relative importance of each criterion, and 3) being imprecise by not prescribing the number of criterion required to qualify for the social marketing label (French and Russell-Bennett, 2015; Wettstein and Suggs, 2016). Contributing to these limitations, we highlight a point made by McHugh and Domegan (2013) contending that the existing lists facilitate a reductionist approach to social marketing design and planning. A reductionist approach emphasises micro-managerial approaches to complex social issues, views individuals as ‘in charge' and responsible for behaviour change, and thus directs attention to changing individual behaviour, as well as largely views social change solutions within a frame of organised simplicity (e.g. 'don't smoke', 'don't drink') (McHugh and Domegan, 2013). When the aim is to influence a particular segment of one community with a clear, well-defined individually valenced behaviour (e.g. cleaning up pet waste in public contexts; picking up litter) a reductionist approach potentially is appropriate. Nonetheless, the social marketing benchmarks cannot be all things to all people in a complex social change environment. Continuing to view social marketing within a narrow, micromanagerial lens constrains the ability of social marketers to be reflexive in searching for new 
opportunities and, importantly, engaging in alternative problem solving and planning approaches (Gordon and Gurrieri, 2014). The value of engaging reflexivity, as Gordon and Gurrieri (2014) point out, becomes particularly important when dealing with complex social issues, such as intoxicated consumption, that are inherently embedded within a wider ecosystem.

Our positioning in this paper aligns with and responds to Kotler \& Zaltman (1971), as well as Andreasen’s (1995), earlier conceptualisations of social marketing which advocate for engagement with more actors within the eco-system (e.g., organisations, government and nongovernment service providers, and policy makers) rather than focusing on individual consumers (i.e., the target audience) who exhibit or are prone to bad behaviour. Similarly, McKenzie-Mohr’s (1996) community-based approach for social marketing holds the same sentiment and defines a clear purpose of engaging with wider audiences to effect change. His object is to address complex, systemic problems and, in doing so, he criticises social marketing's over reliance on rational economic models (i.e. individuals making rational choices) (McKenzie-Mohr and Schultz, 2014).

In continuing these earlier discussions about other actors being involved in social change, we draw upon DrinkWise as a non-profit organisation that applies a social marketing mindset to address alcohol misuse in Australia. From its inception in 2005 DrinkWise's alcohol change initiatives have been underpinned by a social marketing behavioural philosophy to bring about sustained, multi-faceted positive social change across multiple targets such as parents and young adults. The following section explores the social marketing capabilities of this non-profit organisation which has made a 20 year commitment to creating a safer drinking culture, by examining its most recent campaign: How to Drink Properly. Their approach to addressing alcohol cultural change, alongside a long-term generational 
perspective, differentiates DrinkWise from other alcohol prevention approaches, such as those used by government (Previte et al., 2014).

\section{The How to Drink Properly Case}

The following descriptive case analysis of the DrinkWise ‘How to Drink Properly’ (HTDP) alcohol social change initiative applies the NSMC benchmark criteria to analyse their capability to plan and design an alcohol social change program. Our analysis, presented in the following discussion, was informed from a range of data sources provided by DrinkWise relating to HTDP planning and media tracking. Such data sources included a range of qualitative and quantitative market research reports emanating from the HTDP formative research phase and summative tracking studies reporting on target audience reception and response to advertising message and calls to reduce their drinking. The authors also conducted interviews with DrinkWise Board members and commissioned advertising agency personnel, as well as with DrinkWise marketing staff and the DrinkWise CEO.

The HTDP initiative was originally conceived in mid-late 2013, with Phase 1 put to market in February 2014 and Phase 2 put to market in November 2014. The initiative continues as an investment to influence young adults’ (18-24 years) alcohol consumption. Figure 1 presents a timeline of HTDP campaign development and implementation from initial seeding to direct attention young adults drinking behaviour until the completion of the in-market component of Phase 2.

HTDP engages a customer orientated focus based on an 18 month formative research process (Pigram, 2015) that investigated: 1) the social realities of a young adult's drinking journey on a night out; 2) key triggers influencing irresponsible and responsible alcohol decision-making; 3) what makes a good night versus a bad night out; 4) young adult peer-topeer dynamics when socialising with alcohol; 5) the application of European young adult 
alcohol segmentation profiling to the Australian context, and; 6) types of messaging to shift young adults attitudes to irresponsible drinking.

\section{INSERT FIGURE 1 ABOUT HERE}

Leveraging an alternate social behaviour within the alcohol change marketplace, the HTDP behavioural focus positions 'drinking properly’ as aspirational with the aim of empowering young adults to reconsider their drinking choices by taking control of their drinking patterns when socialising. Insights from the formative research data uncovered: 1) responsible drinking is viewed in the same vein as 'self-aware, 'mature' and 'balanced'; 2) damaging reputation and personal standing within a peer group is of critical importance, and; 3) too much forgiving of irresponsible drinking by peers leads to eventual isolation/rejection and exclusion from social events. Cognisant of minimising the barriers and competition, DrinkWise saw an opportunity to develop an alcohol social change strategy on three key areas: loading and control addressing aspects of drinking behaviour; reputation and belonging referring to the 'consequences' and 'social risk' of binge drinking; and empowerment enabling young adults to make responsible drinking choices resulting in group acceptance and inclusion in future social occasions. HTDP maximises the exchange benefits of ‘drink properly’ aspiring to maintaining control, enhancing personal reputation, better understanding personal limits, managing liability status, alongside empowering young people to view ‘drinking properly’ as mature and classy, as opposed to being that girl/guy who stands out at the end of the night for the wrong reasons.

Four well-researched psychographic segments were tested during the formative research stage. The segments include Sensibles (those who stop drinking before getting tipsy); Good Timers (who like to have a drink and find it enjoyable but usually stay within limits); 
Shamefuls (who sometimes drink too much and feel embarrassed about being drunk in front of others) and Hard and Heavies (who love a big night out and get drunk as part of a great night out). Particular attention was directed to understanding moderate drinking as a facilitator of social interactions within the key segments. DrinkWise specifically shifted the profiling lens beyond a signification of 'drinking as a problem' towards moderate drinking as a facilitator of a 'good night out'. Of the four psychographic profiles, DrinkWise selected two key segments—-Good Timers and Shamefuls—as key targets for their ability to provide positive role modelling for the other segments.

In seeking to design alternative intervention mixes, HTDP actively engaged social media platforms, such as Snapchat, Twitter and Facebook, as they represent channels of relevance for the target audience. The value of integrating a variety of social media platforms is the insitu capability to reach young adults at key points throughout their night out drinking journey enabling HTDP to be active where and when young adults are drinking. Additionally, these channels allow young adults to co-create and share the ‘drink properly' brand. The social media strategy was further supported with in-situ drinking event activations designed to leverage one-to-one engagement with the HTDP brand (e.g., Schoolies, Island Parties, music events), with merchandising extending the reach of the HTDP brand (e.g., the Schoolies bag included branded products such as sunglasses, sleeping masks, water bottles, coasters, phone wallets for credit cards and room keys).

However, in order to be where the action is taking place, when it is taking place, such social marketing requires multi-level engagements of partners and stakeholders, such as police, youth groups, alcohol retailers, music festival organisers, and so on. These actors have different conceptions of value, different resources to invest, different outcomes expected, and multiple methods will be needed to approach them. Furthermore, the flows and interactions between participants will change the nature of the exchange as co-creation and destruction of 
value dynamically transforms throughout the process. This dynamic shaping of value is not captured in extant social marketing benchmarking whereby objectives are set in advance and effectiveness is measured at the end of a pre-defined process. The iterative nature of social change requires a new way of thinking about social marketing action.

Well-established communication theory models, such as the Hierarchy of Effects Model (Vaughn, 1986) guided the intervention design. This limited use of theory to inform social marketing programs is not unusual (Luca and Suggs, 2013) and may well reflect reliance on stand-by theories (e.g. Theory of Planned Behaviour). DrinkWise’s focus on communication models influenced how it approached measuring the effectiveness of campaign. For example, Figure 2, based on market research tracking data, illustrates positive recognition of the campaign across Phase 1 and Phase 2 with higher levels of recognition resulting from Phase 2. Recognition was positive because they liked the ad (see Figure 3). Overreliance on individual effectiveness measures maintains an individual orientation to effecting change; this is despite formative research evidencing the importance of cultural and group network effects to influence moderate drinking (e.g., Previte et al., 2015).

These models adequately address individual behaviour change goals. Nonetheless, the value shaped by the multiple actors who participate in the system is not currently understood. In the longer term, each of these actors will have to be able to articulate any value - especially relating to their own goals - that is gained from the exchange before system-wide social change can be said to be achieved or will be sustained. If the exchange is asymmetrical, equilibrium will be sought 'later' and there may be a backlash (e.g., transgressive drinking, reactance, refusal to participate in future activations). Furthermore, as dynamic systems grow and change, participants will change their minds about what constitutes value. As a consequence, social marketers need models that accept the potentiality of outcomes changing 
as a result of the process of change: intuiting and disrupting rather than codifying and forecasting may be required.

INSERT FIGURE 2 ABOUT HERE

\section{INSERT FIGURE 3 ABOUT HERE}

We argue that this descriptive analysis of HTDP is constrained by the utilitarian, reductionist nature of the benchmark criteria which views social marketing as a checklist set of specific activities that fulfils the task of HTDP meeting the label 'social marketing'. What these current benchmark lists leave unchallenged is the bigger question of transformative change which is specifically needed when attempting to effect long-term cultural change or when addressing complex social problems that are inherently influenced by wider social forces. A transformative change transitions the conceptualisation of social marketing as a set of value shaping activities that shape markets (Lefebvre, 2012) where the focus moves beyond 'prodding individuals' to change their behaviour towards the 'shaping of markets and creation of value within markets'. The following section puts forward a rationale, as a means to address the insufficiencies of the current benchmark lists, for moving towards the use of dynamic indicators and directing social marketing thinking to a wider systems purview.

\section{The benchmark criteria disrupted}

In this section we disrupt the benchmark criteria by delineating a new social-ecologically systems-driven framework to assist the design and planning of social change programs. This new delineation - the Indicators for Social Change Framework (see Table 1) - builds on 
recent developments in social marketing, which have been influenced by the broader shifts in marketing thinking that include pervasive discussions about utility and application of cocreation of value, relational thinking, networks of influence and systems thinking to social marketing (e.g., Brennan et al., 2016; Domegan et al., 2016; Luca and Suggs, 2015; Lefebvre, 2012; Vargo et al., 2008). The Indicators for Social Change Framework puts forward a series of 'must have' conceptual indicators to guide the design and planning of social change programs. We delineate across different social marketing orientations that address traditional individual behaviour change and more recent interpretations to integrate a systems-wide approach to effecting social change. By specifying change as occurring across different levels within an eco-system, we delineate the types of marketing actions required for a micromanagerial approach to change (Individual Orientation), and those required for a systems change approach (Systems Orientation). In a systems orientation the indicator actions point to an ecology where the 'individual' is but one participant in a broader scope of social change activities. Within the system, individuals engage in and with wider structural contexts where behaviours are produced (Wallack, 2000) and where social change results from relational interactions within a wider marketplace. For the purpose of this conceptualisation of the Framework, a systems orientation is inclusive of both meso and macro systems layers. Previous discussions by Brennan et al. (2016) explain these differences and they are therefore not addressed explicitly here, as it is beyond the scope of this paper to revisit this distinction.

\section{INSERT TABLE 1 ABOUT HERE}

Acknowledging Wettstein and Suggs (2016) emphasis on procedural structures of process integrity and process quality, our conceptualisation of the Indicators for Social Change Framework extends utility of the term 'indicators' to imply a process for developing social 
change rather than a focus on performance outputs. This utilisation of the term 'indicator' signifies the process of developing social change programs is as important, if not more important, than the outcome.

This subtle shift in nomenclature, from benchmark to indicator, permits a wider comprehension of what is social marketing alongside what can be considered as legitimate outcomes to expect from a social marketing program. The term 'indicators' brings an holistic, abstract interpretation to a phenomenon of interest. Viewing social change as occurring within an ecosystem leverages the interpretation of 'indicators' as a concept reflecting plasticity of a shared common attribute (Heink and Kowarik, 2010). Plasticity infers adaptability of an indicator across different types of social marketing targeting change at different levels within the system. For example, the indicator of value shaping may be interpreted as a marketplace exchange for individual behaviour change whereas it may refer to co-creation of value when considering system-wide social change. Additionally, an indicator infers actions viewed within parameters as opposed to benchmarks that infer a baseline that can be readily identified, measured and marked.

Importantly, the indicators presented are interpreted as being dynamic and, as such, are process elements to guide the design and planning social marketing programs. That is, indicators provide social marketers with the flexibility to adapt to a range of levels, markets and possible outcomes. Our framework does not purport to specify indicator measurement indices. Nonetheless, integrating indicators within programs that take a wider systems approach will need to be both summative and formative (Avkiran and Morita, 2010). Formative indicators are those where ongoing feedback is provided in order to build program integrity and lower risk as means to improve the likelihood that the program will be effective, particularly for building sustainable change. Summative indicators are those where effectiveness is measured as an outcome of the program across all actors. 
French and Russell-Bennett's (2015, p. 149) extension of the benchmark criteria calls for social marketers to leverage the 'must have principle' of social value creation through a reciprocal exchange of resources or assets at the individual, community, societal or global level. The focus on social value creation recognises that individuals operate within and across levels of society, and that solutions are co-created and re-created between individuals and groups in society (Brennan et al., 2016; McHugh and Domegan, 2013). French and RussellBennett extend this relational thinking to outline and advance a theoretical base from which a specific hierarchy of principles, concepts and techniques can inform and guide a social marketer's ability to manage social change outcomes. Whilst on the one hand, such specificity can be important in providing certainty for a planned approach to design social change, it is also restrictive, particularly in complex contexts where a multiplicity of participants (actors) can impact social outcomes and what becomes accepted as the benchmark 'success metric' for improved societal outcome. Although these authors denote a relational thinking perspective, their proposed conceptual model is defined as hierarchical implying either a top-down or bottom-up approach to theorising social marketing. In critiquing the above mentioned iterations of the social marketing criteria we do not argue that behaviour change is unnecessary or no longer worthwhile, but rather we suggest that when considering social markets there is more than one type of market and social value proposition to consider. These broader considerations are constrained by simply considering a "specific behaviour" that any single actor needs to change.

Whilst we align with French and Russell-Bennett’s positioning of social value as a fundamental principle that sits at the heart of social marketing, we believe their conceptualisation of social value is constraining. In privileging an exchange of value view French and Russell-Bennett shape value as a social marketing program outcome. This suggests value results from an exchange offer that emanates from a social marketers 
perception of value, which is then presented to the market for consumer use (Gummerus, 2013). Rather than considering value as an entity that is presented to market by producers, we propose value as a process which is continuous and which evolves through the actions and interactions that occur between actors and the sharing of resources. In this way, we construct value creation as a process that evolves from positive, negative and/or asymmetric actor influences (Vargo et al., 2008; Gummerus, 2013). In taking this perspective, we shift the social marketing mindset towards notions of value shaping. Further, we extend the conceptualisation of value in social marketing as a creation process that is shared amongst actors. In our conceptualisation of the Indicators for Social Change Framework we propose that the indicator of 'value shaping' as the dominant organising influence is fundamental in creating social change.

In the following section we explicate and apply the indicators as identified in the Indicators for Social Change Framework, as listed in Table 1, to the context of alcohol social change to further explore and extend the descriptive analysis as presented in the earlier case discussion. We argue that a social change systems approach requires different conceptions of value, approaches to change, research foci, methods and applications of theory than social marketing aimed at individual behaviour change. The HTDP case has highlighted where benchmarking behaviour change has failed to capture the complexities of other changes required within the system. Sustainable social change will be the outcome of multiple actors shaping their own value from participating in the system.

\section{Applying the 'Indicators for Social Change' to an alcohol context}

In applying the Indicators for Social Change framework we specifically select alcohol as the context through which we can explore complexities of a social market. Alcohol is a welldocumented area of social marketing which has been typically framed from an individual 
problem behaviour perspective. As denoted in the previous section we conceptualise the indicator 'value shaping' as a central organising influence to the planning and design of social marketing, and as such value shaping is embedded as an element of each of the remaining indicators. Our discussion makes an explicit departure from more recent conceptualisations of benchmarks (Wettstein and Suggs, 2016; French and Russell-Bennett, 2015) in that we do not explicate an order of importance to the indicators, yet do argue that all indicators are requisite to effective social marketing practice. Moreover, the shift allows for systematic thinking because: 1) you do not need to know every possible variable or all the measures before you start a program, and; 2) unknowable, adaptable and changeable human interactions and actions can be viewed within parameters rather than seeking concrete 'if this, then that' behaviour change outcomes. Our discussion in the following sections firstly addresses the current “individual orientation” approached applied to address problematic alcohol consumption. We then extend our reflection to consider the "systems orientation" approach to explore and extend social marketing's thinking through a systems lens.

Value shaping is the process whereby value is created and shared within the system of activities that constitutes the marketspace. The value shaping process in individual orientation programs typically adopts a social marketing approach that draws upon value propositions which operationalise the costs and benefits of harmful alcohol consumption. Numerous campaigns have portrayed the costs of excessive alcohol consumption within the frame of physical and social risks and where these risks can be mediated by a change in reduced consumption or abstinence. A systems orientation aims to leverage the process of value sharing across individuals, institutions and organisations in the system. The consumer in a systems orientation becomes an empowered participant in the co-creation process. The other actors in the market (institutions and organisations) are also participants in creating value co- 
creation and thus are understood as resource integrators (McColl-Kennedy et al., 2012). In this way, a systems approach views all actors as having potential resources to share and importantly repositions consumers self-generated activities (e.g. their personal knowledge and skillsets) as fundamental contributions of the creation of social change (McColl-Kennedy et al., 2012). HTDP, for example, demonstrates how consumers can become co-creators of social value through their online social media behaviours which were used to spread the ‘drinking properly’ message through friendship groups and other social connections. Additionally, HTDP is premised on the notion that behavioural change has social value. By taking a dynamic view of alcohol socialisation, HTDP conceives young people as being social agents capable of driving and co-creating social change through their online sharing (and support) offered through social media platforms.

The Change approach indicator explicates marketing actions. An individual orientation is grounded in a 'customer' focus where understanding a consumer's behaviour is central to social marketing thinking and practice. This individual level change approach has been critiqued as constraining social marketing, and is even myopic (Brennan et al., 2016; Lefebvre, 2012). The individual orientation typically constructs the consumer as problematic and as a target for 'interventional' behaviour change strategies. For example, numerous campaigns have targeted individual behaviour change strategies to the market of 18-24 year old drinkers to address excessive binge drinking behaviour. In adopting this strategy, many government and non-profit organisations have constructed drinking as a complex and wicked problem that evolves from the bad behaviour of consumers and which needs to be fixed.

In a systems orientation the focus moves to finding solutions rather than changing 'problem' people. A solutions-focus draws attention to inclusivity of relevant multiple actors within the eco-system who contribute and are involved in the process of value co-creation 
and/or co-destruction through market interactions. Relationship interactions between actors, whilst potentially symmetrical or asymmetrical, are dynamic and exist within the system to develop intra-sectoral and cross-sectoral partnerships (e.g. government, non-profits, private organisations) which have an inherent role in shaping and adapting market systems (Lefebvre, 2012). The Road Crew project (Deshpande et al., 2004) is an example of leveraging a systems-solution approach that addressed the complexity of drink driving social change.

Research focus refers to the type and nature of research that informs decision-making and includes methods and approaches used to generate change. Individual orientation privileges methods that provide a deep understanding of consumer's behaviour in relation to the identified problem. For example, the HDTP initiative was informed by a rich profiling of young people’s drinking behaviour, their drinking culture and key influences impacting individual's choices to moderate their drinking, to manage their drinking or engage in intoxicated drinking. The formative research stage was multipronged, engaging ethnographic insight alongside quantitative evaluations of target audiences reception and response to message appeal and recognition (see Figure 2).

A systems orientation directs the lens of enquiry towards an integrative analysis across all actors, encompassing feedback loops of knowledge and information to understand the peaks and fluctuations that influence creating sustainable social change. Insight takes a long-term view of the market and of how social change is co-created, and or destroyed, by actors. This process thus requires an iterative, ongoing approach to research and evidence collecting. Additionally, integrative insight research is more than evaluating an individual's change (e.g. modified behaviour tracking) to collating wider evidence that documents the impact of alcohol social change on market structures (e.g., impact of lock out laws on consumers, entertainers, publicans, taxi drivers, restaurants, etc.). All of these activities are outside the 
scope of a single social marketing campaign but add value to the social system when combined. Furthermore, insight gathered across actors establishes an evidence base that elucidates the interactive process of decision-making made by multiple actors and demonstrates how this impacts sustainable social change from multiple stakeholder viewpoints. In taking a systems view of market interactions, the whole market from government to consumers can be incorporated. This involves the inclusion of key information from multiple sources, such as evidence presented through senate enquiries prior to the introduction of new alcohol laws, as well as understanding the effects of the alcopops tax aimed to curb binge drinking among young adults or implementation of lock out laws at pub/club venues to curb alcohol-fuelled violence. These macro and meso level efforts to influence alcohol consumption engage more than the individual level and require far-reaching systems-level research to fully understand the intervolvement of action and outcome.

Methods approach in an individual orientation refers to the management of the consumer through the marketing mix (e.g., 4Ps approach). The marketing mix approach to change is well documented and is widely successful in effecting change (Kubacki et al., 2015). This success is a key element to creating and sustaining the acceptance of social marketing as a behaviour change tool.

A systems orientation engages a wider purview of how actors within the social system are mobilised to create and sustain social change. The focus is directed to creating and sustaining relationships and collaborations. This may require internal social marketing enabling staff and service-providers to better deliver social value to the market (Smith, 2011). Russell-Bennett et al. (2013) argue that social marketing needs to take greater consideration of meso-level structures, which they refer to as 'design architecture', that has the ability to disrupt, or recreate, contexts and structures to enable engagement in social change. Hello Sunday 
Morning (https://www.hellosundaymorning.org) is an individually focused social change alcohol project that exemplifies meso-level disruption through design architecture. As an online alcohol change facilitator Hello Sunday Morning relies on individual networks and collaborations to support change. Hello Sunday Morning exploits technology that is available 24/7, enables consumers to co-create and share messages to support their alcohol change journey and engages a social change mix directing attention to creating and sustaining network relationships and collaborations. Hello Sunday Morning represents a wider mesolevel social change mix to support individual behaviour change, thus bringing multiple layers together within the social change system (Fry, 2014).

Theoretical frameworks are the epistemologies and ontologies and the related axiological stances that pervade the choices programs make about their approaches to social change. These belief systems bound the programs because of the way they view the process of change. In an individual orientation, the prevailing belief is that individuals can be changed (not just nudged) by marketing and market behaviour. Thus, the models and theories are individually focussed (e.g. the theory of planned behaviour, advertising response models, etc.). In systems orientations, where the scale of change is larger, relevant theories will be multi-level and actor focussed such as institutional theory and theories of public policy (e.g. health economics, neoliberal framing of policy of the responsible consumer, structuration). The focus centres on finding what works or does not work for a particular set of circumstances. It does not seek to codify a dynamic, morphing social change landscape. In systems thinking, the logic underpinning choice of theory to frame decision making is that of accepting that change is occurring dynamically and that extant theories may be insufficient - and press on while theory catches up. While we do not advocate working in an atheoretical manner, in evolving disciplines, such as social marketing, adapting and testing theories for the context may take 
longer than the situation permits. Co-created outcomes might also produce new theories about what works and why. In HTDP, the focus on evaluating individual's behaviour change obscured opportunities for considering how the multiple actors in the system shaped their own value from the program. As such, it is not known if the social change that was initiated is sustainable over time.

\section{Concluding thoughts}

Despite the longevity of social marketing as an approach to enable social good, contemporary social marketing is witnessing an era of further debate and discourse concerning emerging paradigms, approaches and perspectives in the field (Gordon et al., 2016). As French and Russell-Bennett (2015) note, this ongoing dialogue becomes critical for theory advancement and for refining understanding of social marketing as the discipline advances. It is within this frame that this paper contributes to the continuing debate concerning social marketing practice. Specifically, the paper aims to advance understanding of social marketing's influence within a context where behaviour change results from relational performances within social markets and where multiple actors across layers of a social system (e.g., macro, meso, micro) contribute to sustainable social change outcomes (Brennan et al., 2016). In doing so, this paper contributes to the broadening and deepening of social marketing; and perhaps sparks debate by significantly shifting the nomenclature framing of social marketing towards a social change ecosystem purview.

The Indicators for Social Change Framework contributes to the transformation of social marketing by first identifying that social marketing for individual behaviour change potentially involves alternate marketing actions and activities than those required for wider systems social change. We contend that behavioural change does not occur in a vacuum. As such, we point to an ecology where the individual is but one participant in a broader scope of 
marketing activities. The framework delineates a set of marketing actions to consider when designing for individual behaviour change, and another set of actions to consider when designing for system-level social change. This new delineation of marketing actions is not exhaustive, yet engages a new way to conceptualise social marketing thinking which aims to encourage social marketers to be more reflexive of the wider eco-systems in which social problems arise and how social change programs are designed and planned to effect social change. It permits social change activities to be designed for the appropriate market level.

Second, the Indicators for Social Change Framework places fundamental importance on the indicator 'value shaping' as a central organising influence to the planning and design of social marketing, and value shaping is embedded as an element that shapes and influences the remaining indicators. We extend the conceptualisation of value shaping in social marketing as a creation process that is shared amongst actors, thus propose value as a dynamic entity that does not remain static but rather is evolving and potentially unpredictable (McHugh and Domegan, 2013).

Third, the Indicators for Social Change Framework actively transitions the logic of social marketing towards a mindset that encourages and supports social change planners to be inclusive of interactions, processes and outcomes of value creation across the wider social marketing system. Critically, the proposed framework directs consideration to the 'social' in social marketing and draws attention to the transformational potential of social marketing situating behaviour change as operating as a social interaction between actors within a dynamic market system (Fry, 2014; Lefebvre, 2012). It is important to note that whilst we argue for a broader lens to be applied when planning and designing social change programs, we do not suggest that micro-social marketing has become obsolete. While there is still a long way ahead when it comes to integrating an ecosystem philosophy when designing and implementing social change, we suggest that reliance on individual behavioural change 
criteria is limiting the scope of activities, thereby potentially stifling innovation and experimentation.

The indicator framework captures the essence of social marketing focused on creating sustainable change. It includes space for participatory actions and co-creation of value (i.e., permits action in the face of unknown unknowns), and allows for a broader scope of social marketing when it comes to social change situations. It also provides scope for systems thinking and therefore updates previous benchmark criteria in what has become the new landscape for social marketing practice.

This paper closes with a call for scholars and practitioners to continue 'stepping outside the box' to actively engage a wider systems perspective when doing social marketing. In concluding this paper, we identify four potential areas that warrant further reflection and debate or should be the focus of future research:

- This initial conceptualisation of the Indicators for Social Change Framework delineates types of marketing actions to consider when planning for social change across two orientations: individual and systems inclusive of both meso and macro levels. Further discussion, debate and refinement of the Framework will need to be undertaken to explicate facilitating marketing actions required for meso and macro level social change planning.

- Systems change is complex. As such there is a need for better understanding of the system, its networks and relational influences across varying levels of the eco-system. Teasing out relationships and inter-relationships within and across micro-meso-macro levels is needed as a means to fully embrace wider systems-framing of behaviour change, and the concomitant sociality of change, over time. This requires an extension of the Framework to fully consider multi-linked relationship networks across multilayer systems. Empirical evidence and case studies are required to demonstrate the 
effective mapping of the systems under consideration and the networks and linkages between and across levels. This discussion is being progressed in social marketing through the lens of macro-social marketing and its application to industries, such as fast fashion (Kennedy et al., 2017).

- The use of indicators, as opposed to benchmarks, in social marketing is a novel approach. Further investigation is needed to explore their metric ability as a set of indicators which would allow researchers to borrow indicators and begin their own assessment of programs.

- We advocate for social marketing practitioners, academics and others to apply the Indicators for Social Change Framework to explicate its utility to guide social change planning. 


\section{References}

Andreasen, A. (1995), Marketing social change: Changing behavior to promote health, social development and the environment, Jossey-Bass Publishers, San Francisco.

Andreasen, A. R. (2002), "Marketing social marketing in the social change marketplace”, Journal of Public Policy \& Marketing, Vol. 21 No. 1, pp. 3-13.

Avkiran, N. K., and Morita, H. (2010), "Benchmarking firm performance from a multiplestakeholder perspective with an application to Chinese banking”, Omega, Vol. 38 No. 6, pp. 501-508.

Biroscak, B. J., Schneider, T., Panzera, A. D., Bryant, C. A., McDermott, R. J., Mayer, A. B., Khaliq, M., Lindenberger, J., Courtney, A.H., Swanson, M.A., Wright, A.P. and Hovmand, P.S. (2014), “Applying Systems Science to Evaluate a Community-Based Social marketing Innovation A Case Study”, Social Marketing Quarterly, Vol. 20 No. 4, pp. 247-267.

Brennan, L., Previte, J. and Fry, M.L. (2016), “Social marketing's consumer myopia: applying a behavioural ecological model to address wicked problems", Journal of Social Marketing, Vol. 6 No. 3, pp. 219-239.

Deshpande, S., Rothschild, M.L. and Brooks, R.S. (2004), "New product development in social marketing”, Social Marketing Quarterly, Vol. 10 No. 3-4, pp. 39-49.

Dibb, S. (2014), “Up, up and away: social marketing breaks free”, Journal of Marketing Management, Vol 30 No.11-12, pp.1159-1185.

Domegan, C., McHugh, P., Devaney, M., Duane, S., Hogan, M., Broome, B. J., Layton, R.A., Joyce, J., Mazzonetto, M. and Piwowarczyk, J. (2016), "Systems-thinking social marketing: conceptual extensions and empirical investigations”, Journal of Marketing Management, Vol. 32. No 11-12, pp. 1123-1144.

Dooley, J.A., Jones, S.C. and Desmarais, K. (2006), "Strategic social marketing in Canada: ten phases to planning and implementing cancer prevention and cancer screening campaigns”, Social Marketing Quarterly, Vol. 15, No. 3, pp. 33-48.

French, J. and Blair-Stevens, C. (2005), The Big Pocket Guide to Social marketing, 1st ed., National Social marketing Centre, The National Consumer Council, London.

French, J. and Russell-Bennett, R. (2015), “A hierarchical model of social marketing”, Journal of Social marketing, Vol. 5 No. 2, pp. 139-159.

Fry, M.L. (2014), "Rethinking social marketing: towards a sociality of consumption”, Journal of Social Marketing, Vol. 4 No. 3, pp. 210 - 222.

Gordon, R. and Gurrieri, L. (2014), “Towards a reflexive turn: Social marketing assemblages”, Journal of Social Marketing, Vol. 4 No. 3, pp. 261-278.

Gordon, R., Russell-Bennett, R. and Lefebvre, C.R. (2016), "Social marketing: The state of play and brokering the way forward”, Journal of Marketing Management, Vol. 32 No. 1112, pp. 1059-1082.

Gracia-Marco, L., Vicente-Rodriguez, G., Borys, J., Le Bodo, Y., Pettigrew, S. and Moreno, L. (2011), "Contribution of social marketing strategies to community-based obesity prevention programmes in children”, International Journal of Obesity, Vol. 35 No. 4, pp. 472-479.

Gummerus, J. (2013), "Value creation processess and value outcomes in marketing theory: Strangers or siblings?”, Marketing Theory, Vol. 13 No. 1, pp. 19-46.

Heink, U. and Kowarik, I. (2010), "What are indicators? On the definition of indicators in ecology and environmental planning”, Ecological Indicators, Vol. 10 No. 3, pp. 584-593.

Kennedy, A.M., Kapitan, S., Bajaj, N., Bakonyi, A., and Sands, S. (2017), "Uncovering wicked problem's system structure: seeing the forest for the trees”, Journal of Social Marketing, Vol. 7 No. 1 (ahead of print: http://www.emeraldinsight.com/doi/abs/10.1108/JSOCM-05-2016-0029)

Kotler, P. and Zaltman, G. (1971), "Social marketing: An approach to planned social change”, Journal of Marketing, Vol. 35 No. 3, pp. 3-12. 
Kubacki, K., Rundle-Thiele, S., Pang, B. and Buyucek, N. (2015), "Minimizing alcohol harm: A systematic social marketing review (2000-2014), Journal of Business Research, Vol 68, pp. 2214-2222.

Lefebvre, C. (2012), “Transformative social marketing: co-creating the social marketing discipline and brand”, Journal of Social Marketing, Vol. 2 No. 2, pp. 118-129.

Llauradó, E., Aceves-Martins, M., Tarro, L., Papell-Garcia, I., Puiggròs, F., Arola, L., PradesTena, J., Montagut, M., Moragas-Fernandez, C.M., Sola, R. and Giralt, M. (2015), “A youth-led social marketing intervention to encourage healthy lifestyles, the EYTO (European Youth Tackling Obesity) project: A cluster randomised controlled trial in Catalonia, Spain”, BMC Public Health, Vol. 15, pp. 607-618.

Luca, N.R. and Suggs, L.S. (2013), “Theory and Model Use in Social marketing Health Interventions”, Journal of Health Communication, Vol 18 No. 1, pp.20-40.

Lynes, J., Whitney, S. and Murray, D. (2014), 'Developing benchmark criteria for assessing community-based social marketing programs: A look into Jack Johnson’s “All at Once” campaign”, Journal of Social Marketing, Vol.4 No.2, pp. 111-132

McColl-Kennedy, J. R., Vargo, S. L., Dagger, T. S., Sweeney, J. C., and van Kasteren, Y., (2012), "Health care customer value cocreation practice styles", Journal of Service Research, Vol. 15 No. 4, pp. 370-389.

McHugh, P. and Domegan, C. (2013), "From reductionism to holism: How social marketing caputres the bigger picture through collaborative system indicators”, in Kubacki, K. and Rundle-Thiele, S. (eds), Contemporary Issues in Social Marketing, Cambridge Scholars Publishing, Newcastle upon Tyne, pp. 78-94.

McKenzie-Mohr, D. (1996), "Promoting sustainable future: an introdution to communitybased social marketing”, Journal of Social Issues, Vol. 56 No. 3, 2000, pp. 543-554.

McKenzie-Mohr, D. and Schultz, P.W. (2014)., "Choosing effective behaviour change tools”, Social Marketing Quarterly, Vol. 20 No. 1, pp. 35-46.

Merritt, R., Christopoulos, A. and Thorpe, A. (2009), "Where are all the products? Are we really doing social marketing or are we doing social sales?”, Social Marketing Quarterly, Vol. 15 No. 2, pp. 5-13.

Pigram, E. (2015), “Talking 'bout my generation - The research process behind DrinkWise's 'Drinking, Do it Properly' campaign”, available at http://www.galkal.com.au/whoweare/elyse-pigram.html (accessed 10 January, 2017).

Previte, J., Fry, M.L., Drennan, J. and Fazal E. Hasan, S. (2015), "Friends or Foes: Group influence effects on moderate drinking behaviors", Journal of Business Research, Vol. 68, pp. 2146-2154.

Previte, J., Brennan, L. and Scott, J. (2014), "Meso-macro-level theory - DrinkWise: Investing in generational social change”, in Brennan, L., Binney, W., Parker, L., Aleti, T. and Nguyen, D. (eds), Social marketing and behaviour change: Models, theory and applications, Edward Elgar, Cheltanham UK, pp. 156-177.

Rundle-Thiele, S., Russell-Bennett, R., Leo, C. and Dietrich, T. (2013), "Moderating teen drinking: combining social marketing and education”, Health Education, Vol. 113 No. 5, pp. 392-406.

Russell-Bennett, R., Wood, M. and Previte, J. (2013), "Fresh ideas: Services thinking for social marketing”, Journal of Social Marketing, Vol. 3 No. 3, pp. 223-238.

Smith, A. (2011), "Internal social marketing: lessons from the field of services marketing”, in Hastings, G., Angus, K. and Bryant, C. (eds), The Sage Handbook of Social Marketing, Sage, London UK, pp. 298-316.

Vargo, S.L., Maglio, P.P. and Akaka, M.A. (2008), "On value and value co-creation: A service systems and service logic perspective”, European Management Journal, Vol. 26 No. 3, pp.145-52. 
Vaughn, R., (1986), "How advertising works: A planning model revisited", Journal of Advertising Research, Vol. 26 No. 1, pp. 57-66.

Wallack, L. (2002), “Public health, social change, and media advocacy”, Social marketing Quarterly, Vol. 8 No. 2, pp. 25-31.

Wettstein, D. and Suggs, S. (2016), "Is it social marketing? The benchmarks meet the social marketing indicator”, Journal of Social marketing, Vol. 6 No.1, pp. 2-17.

\section{Acknowledgements}

All authors were involved in a consultancy project for DrinkWise to independently review and critique the 'How to Drink Properly' Campaign during 2015. Brennan has served on the DrinkWise social marketing advisory committee and subsequently as a board member. Previte has also served on the social marketing advisory committee. 


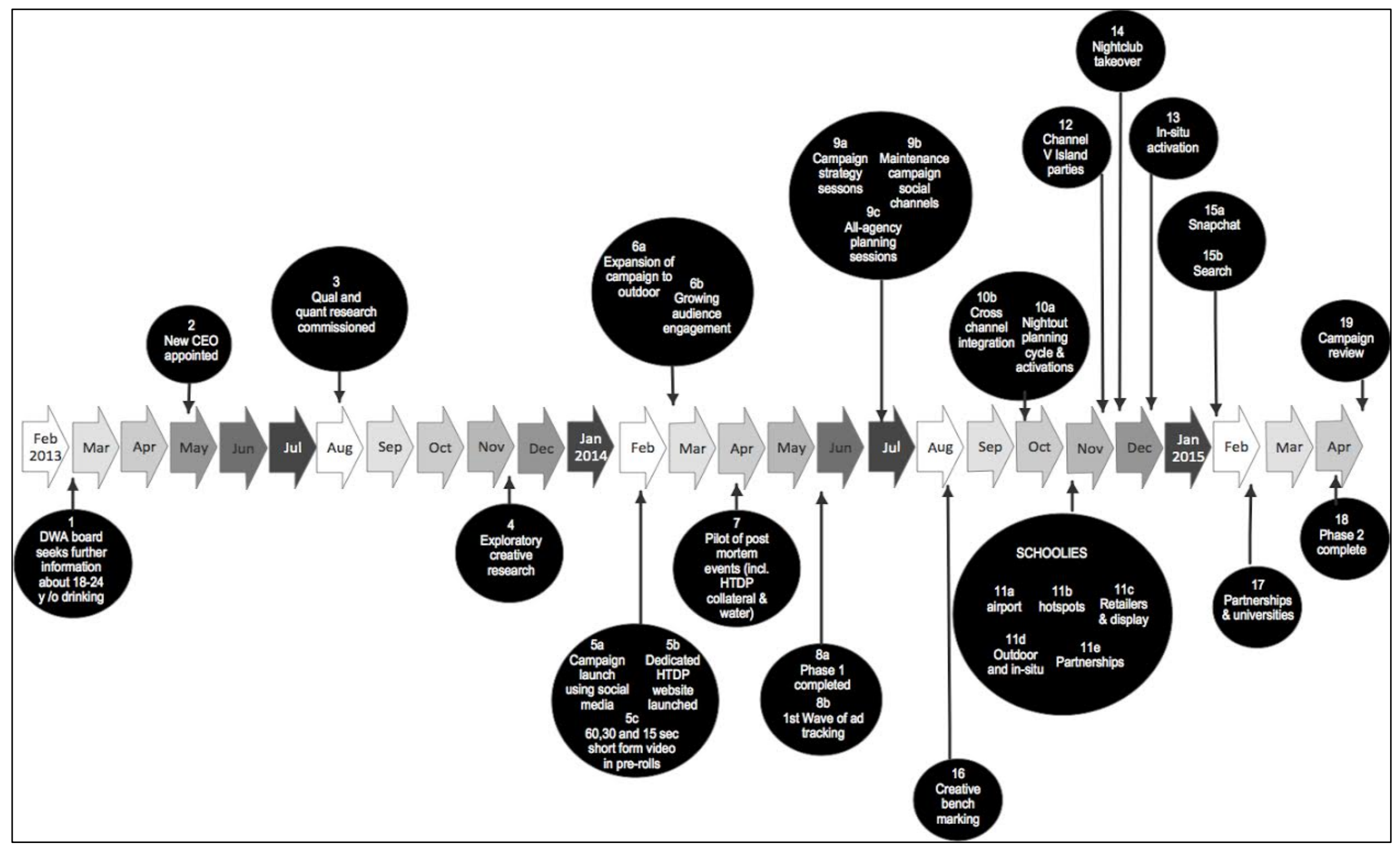

Figure 1. HTDP campaign development timeline 


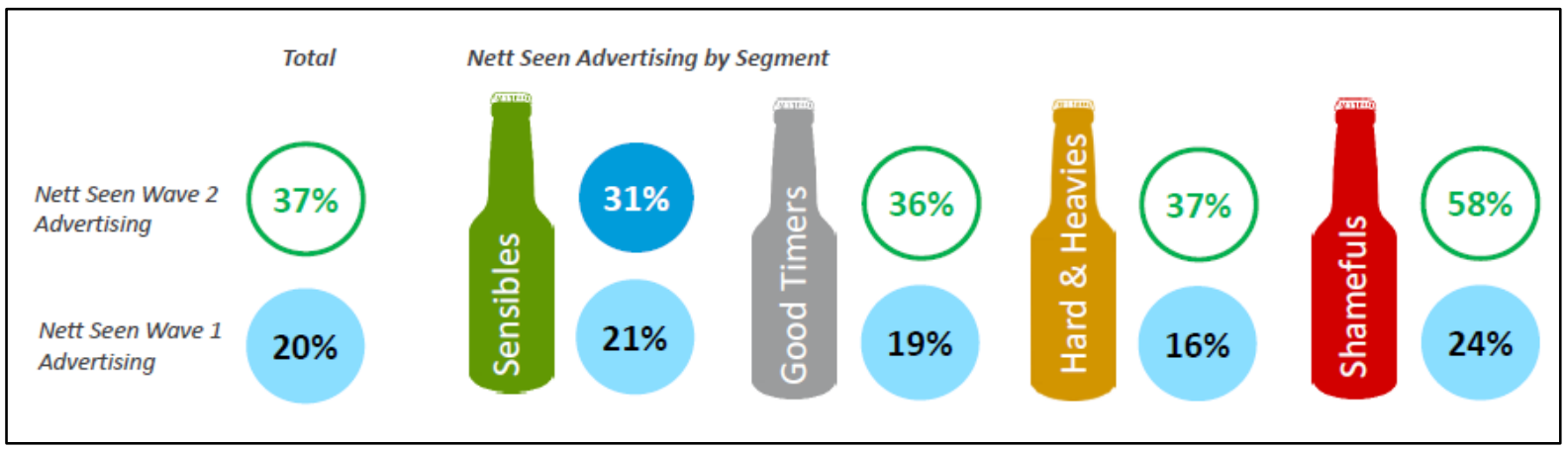

Figure 2. HTDP Communication recognition (Source: Quantum Market Research Wave 2, May 2015)

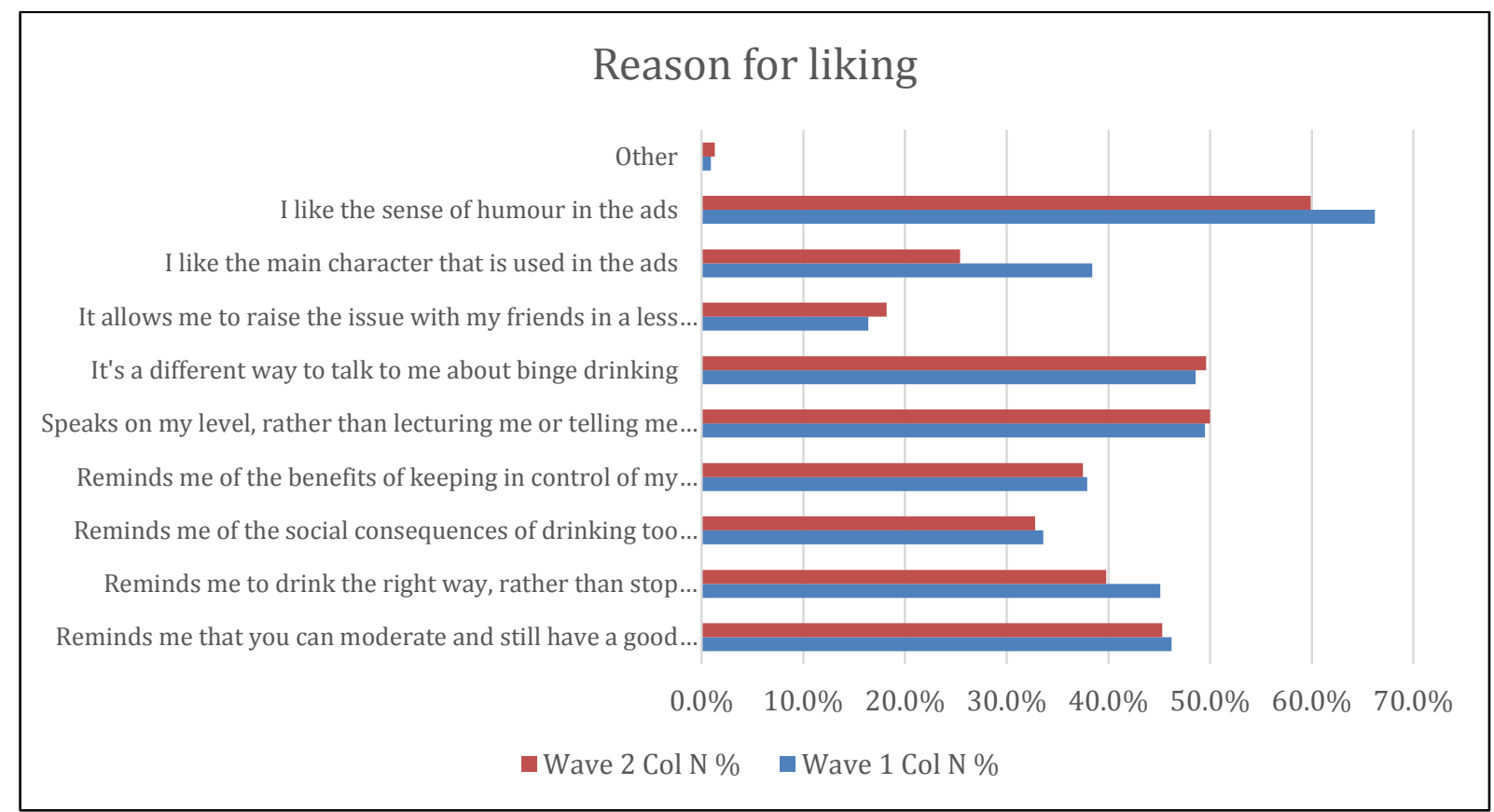

Figure 3. Reason for liking HTDP

Table 1: Indicators for Social Change Framework

\begin{tabular}{lll}
\hline Indicators & Individual Orientation & Systems Orientation \\
\hline Value shaping & Marketplace exchange & Co-creation of value \\
Change approach & Customer-problem focus & System-solution focus \\
Research focus & Insight (individual) & Insight (integrative- networks/collaboration) \\
Methods approach & Marketing mix & Social change mix \\
Theoretical framework & Cognitive models & Pragmatic, mixed models \\
\hline
\end{tabular}

NB: Value shaping is purposely highlighted to indicate it's the dominant influence 